\title{
Population Structure of the Late Blight Pathogen Phytophthora infestans in a Potato Germplasm Nursery in Two Consecutive Years
}

\author{
Yuee Tian, Junliang Yin, Jieping Sun, Hongmei Ma, Yunfang Ma, Junli Quan, and Weixing Shan
}

College of Plant Protection and State Key Laboratory of Crop Stress Biology for Arid Areas, Northwest A\&F University, Yangling, Shaanxi 712100, P. R. China.

Current address of Y. Ma: Zhengzhou University of Light Industry, Zhengzhou, Henan 450000, P. R. China.

Accepted for publication 23 February 2015.

\begin{abstract}
Tian, Y., Yin, J., Sun, J., Ma, H., Ma, Y., Quan, J., and Shan, W. 2015. Population structure of the late blight pathogen Phytophthora infestans in a potato germplasm nursery in two consecutive years. Phytopathology 105:771-777.

As the causal agent of late blight on potato, Phytophthora infestans is one of the most destructive plant pathogens worldwide and widely known as the Irish potato famine pathogen. Understanding the genetic structure of $P$. infestans populations is important both for breeding and deployment of resistant varieties and for development of disease control strategies. Here, we investigate the population genetic structure of $P$. infestans in a potato germplasm nursery in northwestern China. In total, 279 isolates were recovered from 63 potato varieties or lines in 2010 and 2011, and were genotyped by mitochondrial DNA haplotypes and a set of nine

simple-sequence repeat markers. Selected isolates were further examined for virulence on a set of differential lines containing each resistance $(R)$ gene $(R 1$ to $R 11)$. The overall $P$. infestans population was characterized as having a low level of genetic diversity and resistance to metalaxyl, and containing a high percentage of individuals that virulent to all $11 R$ genes. Both A1 and A2 mating types as well as self-fertile P. infestans isolates were present but there was no evidence of sexual reproduction. The low level of genetic differentiation in $P$. infestans populations is probably due to the action of relatively high levels of migration as supported by analysis of molecular variance $(P<0.01)$. Migration and asexual reproduction were the predominant mechanisms influencing the $P$. infestans population structure in the germplasm nursery. Therefore, it is important to ensure the production of pathogen-free potato seed tubers to aid sustainable production of potato in northwestern China.
\end{abstract}

Late blight, caused by the oomycete plant pathogen Phytophthora infestans (Mont.) de Bary, is an agriculturally important and devastating disease on potato worldwide and has been the greatest threat to all the major potato production regions in China (Guo et al. 2010). In the past two decades, the frequency and severity of late blight have increased in many parts of the world, posing a serious threat to potato production (Fry 2008). In China, the most famous epidemic of this disease occurred in 1940, resulting in 30 to $50 \%$ yield loss on potato throughout northern China. Total loss is estimated to be $\$ 1$ billion each year (Guo et al. 2010).

The global population structure of $P$. infestans began to change after the 1980s due to migrations (Goodwin 1997). The first was a migration from Mexico to Europe followed by secondary migrations from Europe to other locations worldwide (Fry 2008; Goodwin 1997). It is generally speculated that this migration has strongly increased the genetic diversity of $P$. infestans populations in Europe and also introduced the A2 mating type from Mexico to Europe and other places (Fry 2008; Montarry et al. 2010). Recent studies indicate that the pathogen population in Europe is becoming increasingly diverse following the first detection of the A2 mating type (Andersson et al. 2009; Drenth et al. 1994; Flier et al. 2007).

$P$. infestans is a heterothallic oomycete and reproduces both asexually and sexually. The asexual cycle, consisting of sporangia, enables dramatically rapid population growth in susceptible host tissue. P. infestans can cause symptoms on foliage, stems, and tubers (Fry 2008). Infected tubers can serve as an inoculum source

Corresponding author: W. X. Shan; E-mail address: wxshan@nwafu.edu.cn

*The $e$-Xtra logo stands for "electronic extra" and indicates that one supplementary table is published online.

http://dx.doi.org/10.1094/PHYTO-03-14-0073-R

(C) 2015 The American Phytopathological Society and start an epidemic in the following season. Sexual reproduction occurs when hyphae of opposite mating types interact with each other and induce the formation of antheridia and oogonia that may associate and result in the formation of thick-walled and robust oospores (Drenth et al. 1995). The presence of the A2 mating type makes sexual recombination possible and increases the likelihood of early-season disease outbreaks (Andersson 2007). The presence of oospores presumably contributed to early-season disease in European countries (Brurberg et al. 2011; Widmark et al. 2007).

In China, the A 2 mating type was first detected in Inner Mongolia autonomous region and Shanxi province in 1996. However, previous studies on the characterization of $P$. infestans isolates revealed clonal populations with highly complicated virulence factors in China (Guo et al. 2009; Guo et al. 2010; Li et al. 2013). Results from mitochondrial DNA (mtDNA) haplotyping and restriction fragment length polymorphism analysis led to the suggestion that multiple migrations of $P$. infestans into China have also occurred during past decades (Guo et al. 2010). However, despite the importance of sexual recombination as an additional source of inoculum and genetic variation, there was little information on sexual reproduction within the population of $P$. infestans in the major potato production areas in China.

Populations of $P$. infestans continue to change and late blight management remains a significant challenge to the potato industry. An initial study of $P$. infestans populations in a potato germplasm nursery revealed the introduction of genetically complicated "new" $P$. infestans isolates (Ma et al. 2013). Here, we report on the population genetic analysis of $P$. infestans in a potato germplasm nursery. We evaluated 279 isolates collected from 63 varieties or lines (varieties are defined as those officially recognized and released lines) in 2010 and 2011 using microsatellite markers. Specifically, the objectives of this study were to (i) understand population genetic structure of $P$. infestans in a germplasm nursery for two consecutive years and (ii) determine whether these populations are sexually 
reproducing to determine the contribution of sexual and asexual reproduction or migration to the development of epidemics.

\section{MATERIALS AND METHODS}

Sampling and purification of $\boldsymbol{P}$. infestans. The germplasm nursery, which is in Guyuan, Ningxia, northwestern China, was isolated from commercial potato fields or private potato gardens by more than $5 \mathrm{~km}$. In all, 27 varieties or lines were cultivated in 2010 and 59 in 2011. In total, 23 potato varieties or lines were common for both years (Table 1). Three introduced varieties or lines-B-71240.2 (V16), Shepody (Vd57), and Atlantic (Vd46) — were also cultivated in the nursery. The latter two varieties were cultivated only in 2011 .

Leaves with single lesions were collected at the start of the late blight disease outbreak (less than $10 \%$ of disease incidence). Within a $300-\mathrm{m}^{2}(50$ by $6 \mathrm{~m})$ plot of each potato variety or line, we followed a "Z" pattern and sampled at five different points. Samples of diseased leaves were packed individually in paper bags and delivered in an icebox to the laboratory for isolation. Isolations were made from a piece of sporulating tissue $(5 \mathrm{~mm}$ in diameter) cut from the margin of a leaf lesion and placed abaxial side up under a tuber slice. Tuber slices were incubated at $16^{\circ} \mathrm{C}$ in darkness for 4 to 7 days. Small pieces of mycelium were picked from the upper side of the potato slice and transferred to rye sugar agar (RSA) medium (Caten and Jinks 1968) amended with the antibiotics ampicillin at $100 \mathrm{mg}$ $\mathrm{ml}^{-1}$ and rifampicin at $20 \mathrm{mg} \mathrm{ml}^{-1}$. Storage of $P$. infestans isolates was on rye grains at $8^{\circ} \mathrm{C}$, slightly modified from a described protocol (http://www.euroblight.net).

Mating type determination. Mating types were determined by placing agar plugs of each isolate individually with each of known A1 (NL80029) and A2 (NL88133) isolates on RSA medium. After 10 to 14 days of incubation at $16^{\circ} \mathrm{C}$ in the dark, presence of oospore formation was examined under a microscope. Isolates that produced oospores with the known A1 tester isolates were determined

TABLE 1. Phytophthora infestans isolates and potato varieties or lines in the potato germplasm nursery

\begin{tabular}{|c|c|c|c|c|c|c|c|}
\hline \multirow[b]{2}{*}{ Lines $^{a}$} & \multicolumn{2}{|c|}{$\begin{array}{c}\text { Number of } \\
\text { isolates }\end{array}$} & \multirow[b]{2}{*}{ Lines $^{\mathrm{a}}$} & \multicolumn{2}{|c|}{$\begin{array}{c}\text { Number of } \\
\text { isolates }\end{array}$} & \multirow[b]{2}{*}{ Lines $^{\mathrm{a}}$} & \multirow{2}{*}{$\begin{array}{c}\begin{array}{c}\text { Number of } \\
\text { isolates }\end{array} \\
2011\end{array}$} \\
\hline & 2010 & 2011 & & 2010 & 2011 & & \\
\hline V1 & 4 & 2 & V21 & 5 & 3 & Vd39 & 5 \\
\hline V2 & 4 & 2 & V22 & 4 & 3 & $\mathrm{Vd} 40$ & 6 \\
\hline V3 & 5 & 3 & $\mathrm{Vc} 23$ & 3 & $\ldots$ & Vd41 & 3 \\
\hline V4 & 5 & 2 & $\mathrm{Vd} 23$ & $\ldots$ & 4 & $\mathrm{Vd} 42$ & 2 \\
\hline V5 & 4 & 1 & $\mathrm{Vc} 24$ & 2 & $\ldots$ & Vd43 & 1 \\
\hline V6 & 4 & 1 & $\mathrm{Vd} 24$ & $\ldots$ & 3 & Vd44 & 3 \\
\hline V7 & 4 & 11 & V25 & 3 & 6 & $\mathrm{Vd} 45$ & 4 \\
\hline V8 & 5 & 1 & V26 & 2 & 3 & Vd46 & 2 \\
\hline V9 & 4 & 3 & $\mathrm{Vc} 27$ & 1 & $\ldots$ & $\mathrm{Vd} 47$ & 3 \\
\hline V10 & 5 & 1 & $\mathrm{Vd} 27$ & $\ldots$ & 2 & Vd48 & 2 \\
\hline V11 & 4 & 3 & $\mathrm{Vd} 28$ & $\ldots$ & 2 & Vd49 & 3 \\
\hline Vc12 & 5 & $\ldots$ & $\mathrm{Vd} 29$ & $\ldots$ & 4 & Vd50 & 4 \\
\hline Vd12 & $\ldots$ & 1 & $\mathrm{Vd} 30$ & $\ldots$ & 3 & Vd51 & 1 \\
\hline V13 & 4 & 3 & $\mathrm{Vd} 31$ & $\ldots$ & 3 & Vd52 & 1 \\
\hline V14 & 5 & 1 & $\mathrm{Vd} 32$ & $\ldots$ & 2 & Vd53 & 1 \\
\hline V15 & 4 & 3 & Vd33 & $\ldots$ & 5 & Vd54 & 2 \\
\hline V16 & 5 & 3 & $\mathrm{Vd} 34$ & $\ldots$ & 1 & Vd55 & 1 \\
\hline V17 & 4 & 3 & $\mathrm{Vd} 35$ & $\ldots$ & 5 & Vd56 & 2 \\
\hline V18 & 3 & 1 & Vd36 & $\ldots$ & 6 & Vd57 & 3 \\
\hline V19 & 5 & 1 & $\mathrm{Vd} 37$ & $\ldots$ & 6 & Vd58 & 3 \\
\hline V20 & 5 & 1 & Vd38 & $\ldots$ & 2 & Vd59 & 9 \\
\hline Total & 88 & 47 & $\ldots$ & 20 & 63 & $\ldots$ & 61 \\
\hline
\end{tabular}

a $\mathrm{V}=$ varieties or lines that were cultivated in both 2010 and $2011, \mathrm{Vc}=$ varieties or lines cultivated only in 2010 , and $\mathrm{Vd}=$ varieties or lines cultivated only in 2011. Of 63 potato varieties or lines, 29 (V1, 2, 3, 4, 6, 7, 8, 9, 10, 15, 16, 18, 19, 20, 21; Vd46, 47, 48, 49, 50, 51, 52, 53, 54, 55, 56, 57, 58, and 59) were potato varieties and 34 (V5, 11, 13, 14, 17, 22, 25, 26; Vc12, 23, 24, 27; Vd12, 23, 24, 27, 28, 29, 30, 31, 32, 33, 34, 35, 36, 37, 38, 39, 40, $41,42,43,44$, and 45 ) were potato lines. to be the A 2 mating type and isolates that produced oospores with the known A2 tester isolate were the A1 mating type. Isolates producing oospores with both known A1 and A2 mating types, as well as in single cultures, were referred to as self-fertile isolates (Tantius et al. 1986).

In vitro sensitivity to metalaxyl. The sensitivity of $P$. infestans isolates to the phenylamide fungicide metalaxyl (Baoling Chemical Industry, Jiangsu, China) was evaluated according to the method described by Therrien et al. (1993).

Pathotype determination. A subset of 70 isolates sampled on different potato varieties or lines was selected based on simplesequence repeat (SSR) genotype information and to be representative of the potato varieties or lines from which the pathogen was isolated. A detached-leaf assay was used to assess the pathotype of each isolate on a set of 11 potato near-isogenic lines as differentials that presumably possess a single resistance $(R)$ gene ( $R 1$ to $R 11)$ from Solanum demissum.

Leaves were obtained from the differentials grown from tissue culture plantlets. Fully expanded, young leaflets detached from the middle part of each differential plant at 6 to 10 weeks of age were placed abaxial side up in plastic trays containing moistened filter paper. Each leaflet was inoculated with a $15-\mu l$ drop of a zoospore suspension, which was obtained from a sporangial suspension adjusted to $4 \times 10^{4} \mathrm{ml}^{-1}$ before triggering zoospore production (http://www.eucablight.org/EucaBlight.asp). Three leaflets per isolate were used and the experiment was repeated once. Inoculated leaflets were incubated in a climate chamber at $16^{\circ} \mathrm{C}$ in the dark for 12 to $24 \mathrm{~h}$. The leaflets were then placed adaxial surface up in the plastic trays, covered with plastic wrap, and incubated at $16^{\circ} \mathrm{C}$ with a photoperiod of $14 \mathrm{~h}$ of illumination and $10 \mathrm{~h}$ of darkness. Disease symptoms were scored 4 days after inoculation and again on day 7 . The interaction between $R$ gene and pathogen was considered compatible when sporulation was clearly visible on infected leaflets on at least one of the replicate leaflets in both independent experiments (Flier et al. 2007).

DNA extraction and cloning. $P$. infestans isolates were grown in RSA broth for 10 to 12 days in darkness at $16^{\circ} \mathrm{C}$. The mycelium was harvested, lyophilized in liquid nitrogen, and stored at $-80^{\circ} \mathrm{C}$. Genomic DNA of $P$. infestans was extracted using the protocol described by Goodwin et al. (1992) and stored in Tris-EDTA (10 mM Tris-HCI and $0.1 \mathrm{mM}$ EDTA, $\mathrm{pH} 8.0$ ) at $-20^{\circ} \mathrm{C}$ until use.

mtDNA haplotypes were determined according to the method described by Griffith and Shaw (1998).

Markers used for microsatellite analysis were Pi02, Pi63, Pi4B, Pi4G, G11, D13, SSR4, SSR8, and SSR11 (Knapova and Gisi 2002; Lees et al. 2006; Li 2012). Polymerase chain reaction (PCR) amplification was performed in a $20-\mu l$ volume, as described previously (Lees et al. 2006; Li 2012), using the following conditions: a cycle of $2 \mathrm{~min}$ at $95^{\circ} \mathrm{C}$; followed by 30 cycles of $20 \mathrm{~s}$ at $95^{\circ} \mathrm{C}$, $25 \mathrm{~s}$ at $58^{\circ} \mathrm{C}$ (for $\mathrm{Pi} 02, \mathrm{Pi} 4 \mathrm{~B}, \mathrm{Pi} 4 \mathrm{G}$, and $\mathrm{Pi} 63$ ), $60^{\circ} \mathrm{C}$ (for SSR4, SSR8, and SSR11), $50^{\circ} \mathrm{C}$ (for D13), or $56^{\circ} \mathrm{C}$ (for G11), and $60 \mathrm{~s}$ at $72^{\circ} \mathrm{C}$; and a final extension step of $72^{\circ} \mathrm{C}$ for $5 \mathrm{~min}$. PCR products were separated by electrophoresis in polyacrylamide nondenaturating gels. Gels were silver stained and dried using procedures as described by Bassam and Gresshoff (2007). In order to analyze genetic relationships between $P$. infestans populations from the germplasm nursery, PCR products of selected isolates were cloned into pMD18-T vector and sequenced by GenScript (Nanjing, China).

Genetic data analysis. In order to eliminate the bias imposed by the large asexual reproductive capacity and avoid redundancy in the collection, a "clone-corrected data set" was constructed by including only one representative isolate of each genotype (Chen and McDonald 1996).

To reveal genetic relationships among the detected $P$. infestans genotypes, an unrooted unweighted pair group method with arithmetic means tree based on shared alleles distance was constructed using the binary data with all isolates with PowerMarker software 
v3.25 (Liu and Muse 2005). Phylogenetic trees were visualized by FigTree v1.3.1 (Rambaut and Drummond 2010) using the distance matrix generated by PowerMarker and 1,000 bootstrap replications. Both genotypic and gene diversity were estimated according to the method described by Tian et al. (2014).

The hypothesis of nondifferentiation among populations was tested by comparing the observed $\theta$ value with the value calculated for data sets in which alleles were resampled without replacement (1,000 randomizations) using Multilocus v1.3 (Agapow and Burt 2001 ). Confidence intervals for $\theta$ (equivalent to Wright's $F_{\mathrm{ST}}$ ) were generated by bootstrapping over loci (1,000 replications, 95\% confidence level) (Grünwald et al. 2003). We also assessed whether random sexual reproduction occurred by estimating the index of multilocus linkage disequilibrium $\left(\bar{r}_{\mathrm{d}}\right)$ with the Poppr package (Kamvar et al. 2014) in R v3.0.0 (Team 2011). This index is based on the index of association $\left(I_{\mathrm{A}}\right)$, allowing one to test for random recombination between pairs of loci by comparing the observed and expected variance of genetic distance between all pairs of individuals (Smith et al. 1993). The $\bar{r}_{\mathrm{d}}$ statistic is much less dependent on the number of loci than the $I_{\mathrm{A}}$ (Smith et al. 1993). Departure from the null hypothesis (no linkage disequilibrium; that is, $\bar{r}_{\mathrm{d}}=0$ ) was assessed by permuting alleles between individuals independently for each locus (1,000 permutations). Analyses were conducted with all isolates of a population and clone-corrected data sets.

Analysis of molecular variance (AMOVA) was performed using GenAlEx 6.5 using the standard data setting and 10,000 permutations to determine how the genetic variation is partitioned within and between populations. A principle coordinate analysis (PCoA) was performed using GenAlEx 6.5 with clone-corrected dataset to construct plots of the most significant axes for grouping pattern verification (Peakall and Smouse 2006).

\section{RESULTS}

Characterization of $P$. infestans populations in the germplasm nursery. In total, $279 P$. infestans isolates were obtained during two consecutive years from 29 potato varieties and 34 lines cultivated in a potato germplasm nursery, including 108 isolates collected in 2010 and 171 in 2011 (Table 1).

Nine microsatellite markers distinguished the 279 P. infestans isolates into 26 multilocus SSR genotypes (Table 2; Supplementary Table S1), with 19 genotypes in 2010 and 9 in 2011. Two genotypes (SG-14 and SG-25) were detected in both years, each comprising 54.5 and $14.7 \%$ of the obtained isolates, respectively. SG-14 was dominant in both years (Table 2; Fig. 1). The overall genotypic diversity in $P$. infestans populations was low (Table 3). In total, 27 alleles were detected over the nine microsatellite loci. The mean number of alleles observed per locus in the single populations ranged from 1.8 to 3.0 (Table 3 ).

mtDNA haplotype analysis revealed that 251 of the 254 isolates were mtDNA haplotype Ia, with the exception of three IIb isolates collected from two local main potato varieties (V2 and V8) which have been planted in northern China for nearly 20 years (Table 3 ).

A subset of $44 P$. infestans isolates collected from 15 varieties and 17 lines in both years (19 isolates in 2010 and 25 in 2011) were randomly selected and examined for sensitivity to the fungicide metalaxyl. The results revealed that $42(95.5 \%)$ isolates were resistant. Two isolates from two different potato lines (Vd28 and Vd29) cultivated only in 2011 were moderately resistant. Genotype analysis revealed that the 42 metalaxyl-resistant isolates belonged to eight SSR genotypes and 24 isolates were of the dominant genotype SG-14.

Three pathotypes were identified among the $70 \mathrm{P}$. infestans isolates examined. Isolates were from 20 potato varieties and 21 lines, of which 5 varieties were cultivated in both years. Sixty-six isolates $(94.3 \%)$ were virulent to all $11 R$ genes. The other two pathotypes, 1.2.3.4.5.6.7.8.10.11 and 2.3.4.5.6.7.8.9.10.11, were much less frequent, each represented by two isolates obtained from three potato lines (V11, Vd40, and Vd45) and one local main potato cultivar (Vd59). Isolates from different potato varieties or lines shared the same SSR genotype as well as pathotype (Table 4). The results showed that the majority of the local main potato varieties and a series of potato lines were susceptible to the predominant $P$. infestans population in the germplasm nursery (Table 4).

Lack of sexual recombination was detected in $P$. infestans populations in the germplasm nursery. Mating type assays showed that both A1 and A2 as well as self-fertile isolates were detected in 2010 but only A2 and self-fertile were detected in 2011. Self-fertile isolates were dominant in both years. A1 mating type was only detected in 2010, from two local main potato cultivars that have been planted in northwestern China for nearly 20 years. Isolates from the 40 varieties or lines that were cultivated only in 1 year all belonged to the same mating types (except varieties Vd44 and Vd59).

The highest unbiased expected heterozygosity $\left(H_{\mathrm{E}}=0.294\right)$ were observed in the 2010 and 2010-23 populations, whereas the lowest $\left(H_{\mathrm{E}}=0.250\right)$ was observed in 2011-23. The observed heterozygosity $\left(H_{\mathrm{O}}\right)$ varied between 0.397 and 0.492 . In all the populations, it was higher than the expected heterozygosity and gave a negative fixation index (Table 3 ). The $F_{\text {IS }}$ values were not highly variable among $P$. infestans populations, ranging from -0.378 to -0.770 . Although the negative values for $F_{\text {IS }}$ were observed among all of the $P$. infestans, little difference was observed between $P$. infestans populations (Table 3 ). The $\bar{r}_{\mathrm{d}}$ tests for $P$. infestans populations from two consecutive years showed similar results (Table 5). Tests on all $P$. infestans isolates collected in 2010 and 2011 rejected the null hypothesis of recombination $(P<0.01)$. Similar results were obtained after clone correction. This analysis provided further evidence

TABLE 2. Distribution of Phytophthora infestans simple-sequence repeat genotypes (SG) in the germplasm nursery in 2010 and $2011^{\text {a }}$

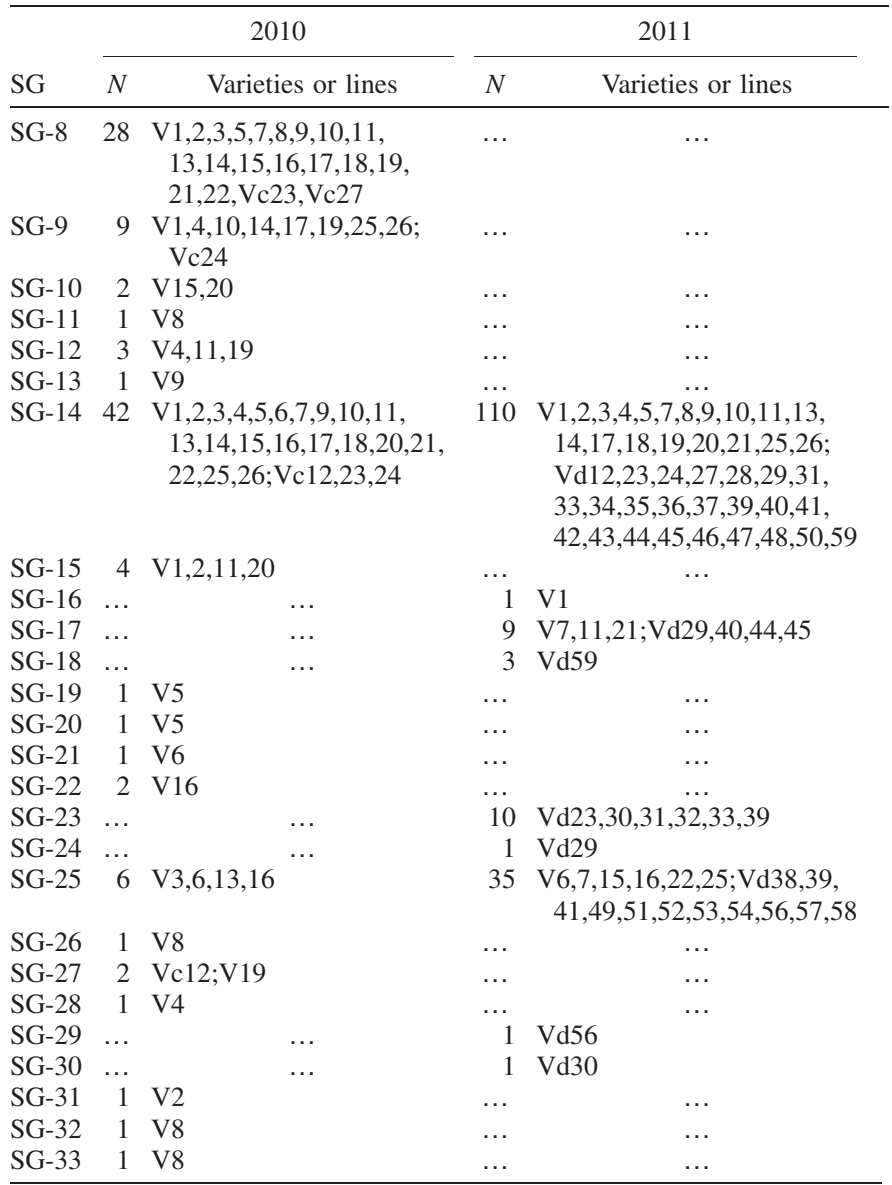

${ }^{a} N=$ number of isolates, $\mathrm{Vc}=$ varieties or lines cultivated only in 2010, and $\mathrm{Vd}=$ varieties or lines cultivated only in 2011 . 
for significant multilocus linkage disequilibria and also supported the hypothesis of clonal reproduction populations.

Low genetic differentiation and strong gene flow among $P$. infestans populations. When $P$. infestans isolates from the common 23 varieties or lines in 2010 and 2011 were considered two different populations, isolates from the other 40 varieties or lines that were cultivated only in a single year (2010 or 2011) formed two subpopulations. Subsequently, SSR genotyping showed that 19 and 4 genotypes were identified in two former populations whereas 4 and 8 genotypes were detected in the two subpopulations, respectively (Table 3).

When $P$. infestans populations were defined by year, 19 and 9 genotypes were identified in 2010 and 2011, respectively. Of the nine genotypes detected in $2011,64.3 \%$ of isolates belonged to the dominant genotype SG-14 (Table 2; Fig. 1). Isolates of five genotypes were recovered from varieties or lines cultivated only in 2011. Two genotypes (SG-14 and SG-25) were recovered from varieties cultivated in both 2010 and 2011. Genotype SG-16 was represented by only one isolate (Table 2). The other genotype (SG17) was represented by nine isolates, including three from three common varieties or lines and six from four varieties or lines cultivated only in 2011.
Regardless of populations defined by sampling year or potato varieties or lines, the results showed that genotypic diversity of P. infestans populations in 2010 was higher than that in 2011 (Table 3$)$. The vast majority of the P. infestans isolates $(93.8 \%)$ recovered from the 23 common varieties or lines in 2011 shared the same SSR genotypes (SG-14 and SG-25) as those in 2010 (Table 2). Low genetic differentiation $(\theta=0.0148)$ and strong gene flow $\left(N_{\mathrm{m}}=16.6\right)$ were observed between $P$. infestans populations in the 2 years. PCoA revealed that the majority of $P$. infestans isolates formed one cluster, with the exception of isolates of five genotypes recovered from varieties or lines cultivated only in 2011 and one genotype of the only three A1 isolates detected in the germplasm nursery (Fig. 2). The AMOVA of microsatellite genotype data revealed that $94.77 \%$ of the genetic variation was found within populations, whereas only $5.03 \%$ was found among populations $(P<0.01)$ (Table 6)

\section{DISCUSSION}

The $P$. infestans population in the germplasm nursery was consistent with clonal population structure. Both phenotypic and genotypic diversity in the $P$. infestans population in the germplasm

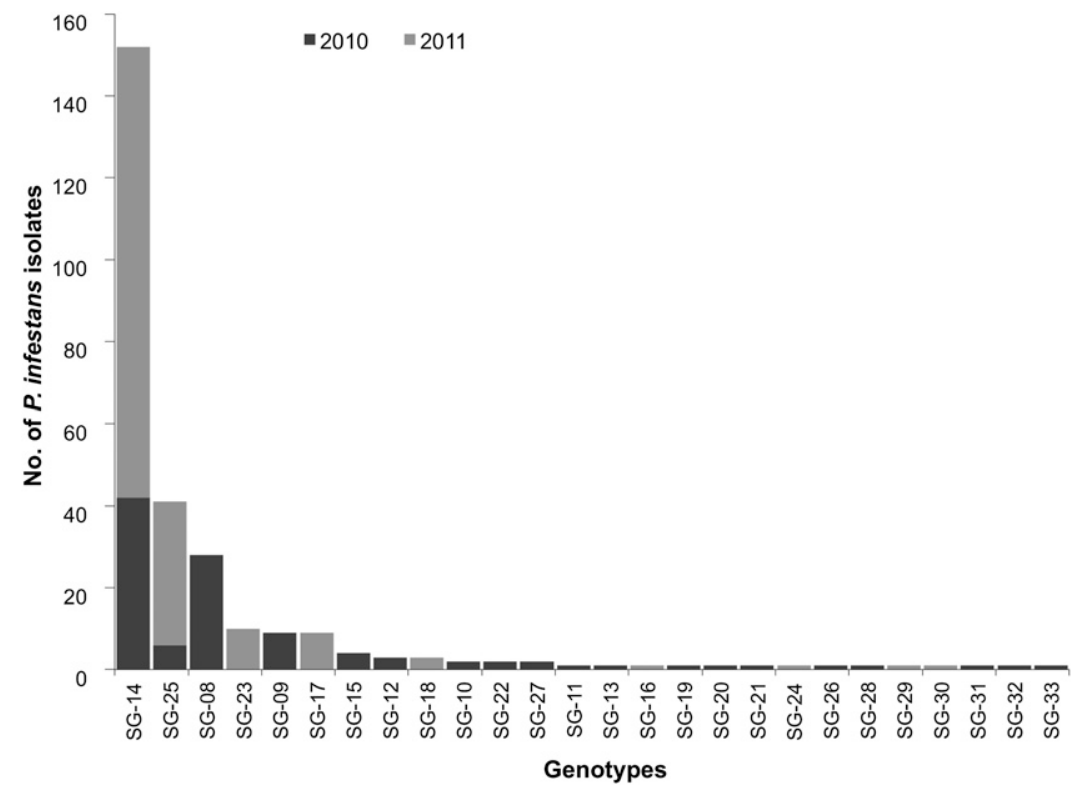

Fig. 1. Number of Phytophthora infestans isolates of each simple-sequence repeats genotypes detected in the germplasm nursery in 2010 and 2011.

TABLE 3. Genetic diversity of Phytophthora infestans populations (Pops) in the germplasm nursery defined by sampling year and varieties and lines

\begin{tabular}{|c|c|c|c|c|c|c|c|}
\hline \multirow[b]{2}{*}{ Statistics $b$} & \multicolumn{2}{|c|}{ Pops by sampling year } & \multicolumn{4}{|c|}{ Pops by varieties and lines ${ }^{\mathrm{a}}$} & \multirow[b]{2}{*}{ Total } \\
\hline & 2010 & 2011 & $2010-23$ & $2010-4$ & $2011-23$ & $2011-36$ & \\
\hline$N$ & 108 & 171 & 97 & 11 & 64 & 107 & 279 \\
\hline MT & $\mathrm{A} 1 / \mathrm{A} 2 / \mathrm{SF}$ & $\mathrm{A} 2 / \mathrm{SF}$ & $\mathrm{A} 1 / \mathrm{A} 2 / \mathrm{SF}$ & $\mathrm{A} 2 / \mathrm{SF}$ & $\mathrm{A} 2 / \mathrm{SF}$ & A2/SF & $\mathrm{A} 1 / \mathrm{A} 2 / \mathrm{SF}$ \\
\hline$N G$ & 19 & 9 & 19 & 4 & 4 & 8 & 26 \\
\hline$H$ & 1.965 & 1.121 & 2.008 & 1.162 & 0.813 & 1.219 & 1.733 \\
\hline$G$ & 4.304 & 2.063 & 4.449 & 2.814 & 1.860 & 2.353 & 3.007 \\
\hline$H_{\mathrm{E}}$ & 0.294 & 0.282 & 0.294 & 0.279 & 0.250 & 0.278 & 0.282 \\
\hline$F_{\text {IS }}$ & -0.585 & -0.635 & -0.378 & -0.502 & -0.444 & -0.770 & -0.408 \\
\hline
\end{tabular}

a Varieties and lines: $2010-23=$ population defined by isolates from varieties cultivated in both years, $2010-4=$ isolates from varieties specifically cultivated in 2010, 2011-23 = isolates from varieties cultivated in both years, and 2011-36 = isolates from varieties specifically cultivated in 2011.

b $N=$ number of isolates, MT = mating type, $\mathrm{mtDNA}=$ mitochondrial DNA haplotype, $N G=$ number of simple-sequence repeat (SSR) genotypes, $H=$ ShannonWiener index of SSR genotype diversity, $G=$ Stoddart and Taylor's genotypic diversity index, $E_{5}=$ index of evenness, $A_{\mathrm{O}}=$ mean number of observed alleles per locus, $H_{\mathrm{O}}=$ observed heterozygosity, $H_{\mathrm{E}}=$ unbiased expected heterozygosity $($ Nei 1973$)$, and $F_{\text {IS }}=$ fixation index. 
nursery were low. Our study indicates that the majority of the local potato varieties and a series of potato lines were susceptible to the contemporary predominant $P$. infestans population.

Several indicators supported the asexual reproduction in the $P$. infestans population in the germplasm nursery. First, the high proportion of repeated genotypes with one genotype dominating in the population provides strong evidence for clonal reproduction. This is similar to the situation in the United States, where

TABLE 4. Distribution of Phytophthora infestans pathotypes from infected potato varieties or lines in the germplasm nursery in 2010 and 2011 ${ }^{\text {a }}$

\begin{tabular}{lc}
\hline Pathotype & Number of $P$. infestans isolates $^{\mathrm{b}}$ \\
\hline A & V1(2),V2(1),V3(2),V4(2),V5(1),V6(2),V7(3),V8(2),V9(2), \\
& V10(3),V11(1), V12(3),V13(3),V14(3),V15(2),V16(3), \\
& V17(2),V18(2),V19(3),V20(1),V21(3), V22(1),V23(1), \\
& V24(1),V25(1),V26(2),V27(2),Vd31(1),Vd36(1),Vd37(1), \\
& Vd38(1),Vd40(1),Vd42(1),Vd49(1),Vd54(1),Vd57(2), \\
& Vd58(1),Vd59(1) \\
B & Vd45(1),Vd59(1) \\
C & V11(1),Vd40(1) \\
\hline
\end{tabular}

${ }^{a}$ Isolates of dominant pathotype A (1.2.3.4.5.6.7.8.9.10.11) were recovered from 38 varieties or lines, and the pathotypes $B$ (1.2.3.4.5.6.7.8.10.11) and C (2.3.4.5.6.7.8.9.10.11) were each recovered from two different varieties or lines.

b Numbers in parentheses indicate the number of $P$. infestans isolates.

TABLE 5. Multilocus linkage disequilibrium $\left(\bar{r}_{\mathrm{d}}\right)$ analysis of Phytophthora infestans populations ${ }^{\mathrm{a}}$

\begin{tabular}{|c|c|c|c|c|}
\hline \multirow[b]{2}{*}{ Population } & \multicolumn{2}{|c|}{ With multicopies } & \multicolumn{2}{|c|}{ Without multicopies } \\
\hline & $\bar{r}_{\mathrm{d}}$ & $P$ value & $\bar{r}_{\mathrm{d}}$ & $P$ value \\
\hline 2010 & 0.216 & $P<0.01$ & 0.173 & $P<0.01$ \\
\hline 2011 & 0.258 & $P<0.01$ & 0.300 & $P<0.01$ \\
\hline 2010 and 2011 & 0.150 & $P<0.01$ & 0.144 & $P<0.01$ \\
\hline $2010-23$ & 0.217 & $P<0.01$ & 0.197 & $P<0.01$ \\
\hline $2010-4$ & 0.382 & $P<0.01$ & 0.126 & $P<0.01$ \\
\hline 2011-23 & 0.649 & $P<0.01$ & 0.732 & $P<0.01$ \\
\hline 2011-36 & 0.497 & $P<0.01$ & 0.117 & $P<0.01$ \\
\hline
\end{tabular}

a Tests were done on data with and without multicopies. Values that differ significantly from 0 indicate a departure from linkage equilibrium.
$P$. infestans populations are also primarily reproducing asexually, with several new clonal lineages (US-22, US-23, and US-24) being derived from a common ancestor and responsible for the late blight epidemics in the northeastern region of the United States (Danies et al. 2013; Hu et al. 2012). In contrast, no particular genotypes were dominant in central Mexico and Nordic European countries, where sexual reproduction was notable (Brurberg et al. 2011; Goodwin et al. 1992; Grünwald et al. 2001). It is worth noting that the population structure of $P$. infestans in this germplasm nursery is very distinct from that in Nordic European countries using a comparable subset of microsatellite markers (Brurberg et al. 2011; Widmark et al. 2007). In the above countries, the SSR genotyping analysis of $P$. infestans isolates revealed a high level of variation of genotypes. In addition, soilborne oospores contributed significantly to initiation of the late blight epidemic in the potato field investigated, and sexual reproduction contributed to the genetic variation of $P$. infestans (Brurberg et al. 2011; Widmark et al. 2007, 2011).

Second, in our study, the observed heterozygosity is higher than that expected under Hardy-Weinberg equilibrium, which gives a negative fixation index. The negative $F_{\text {IS }}$ values indicating an excess of heterozygotes relative to random mating, which could result either from recent migration events or asexual reproduction (Balloux et al. 2003; Goodwin 1997). However, in diploid organisms, it is generally acknowledged that the extreme clonality often results in considerable heterozygote excesses (Balloux et al. 2003; Birky 1996; Prospero et al. 2007).

Third, in our study, the test of $\bar{r}_{\mathrm{d}}$ performed with and without multicopies did allow rejection of the null hypothesis of recombination and indicates that genotypes of the $P$. infestans populations were

TABLE 6. Analysis of molecular variance of Phytophthora infestans populations (pops) in the germplasm nurserya

\begin{tabular}{lrrcc}
\hline Source of variation & \multicolumn{1}{c}{ df } & \multicolumn{1}{c}{ SS } & Variation $(\%)$ & $P$ \\
\hline Among pops & 1 & 10.875 & 5.03 & $<0.01$ \\
Among subpops & 2 & 2.930 & 0.20 & $<0.01$ \\
Within pops & 275 & 364.203 & 94.77 & $<0.01$ \\
Total & 278 & 378.007 & 100.00 & $\ldots$ \\
\hline
\end{tabular}

a $\mathrm{df}=$ degrees of freedom, $\mathrm{SS}=$ sum of squared observations, Variation $(\%)=$ percentage of total variance, and $P=P$ values are based on 1,000 permutations.

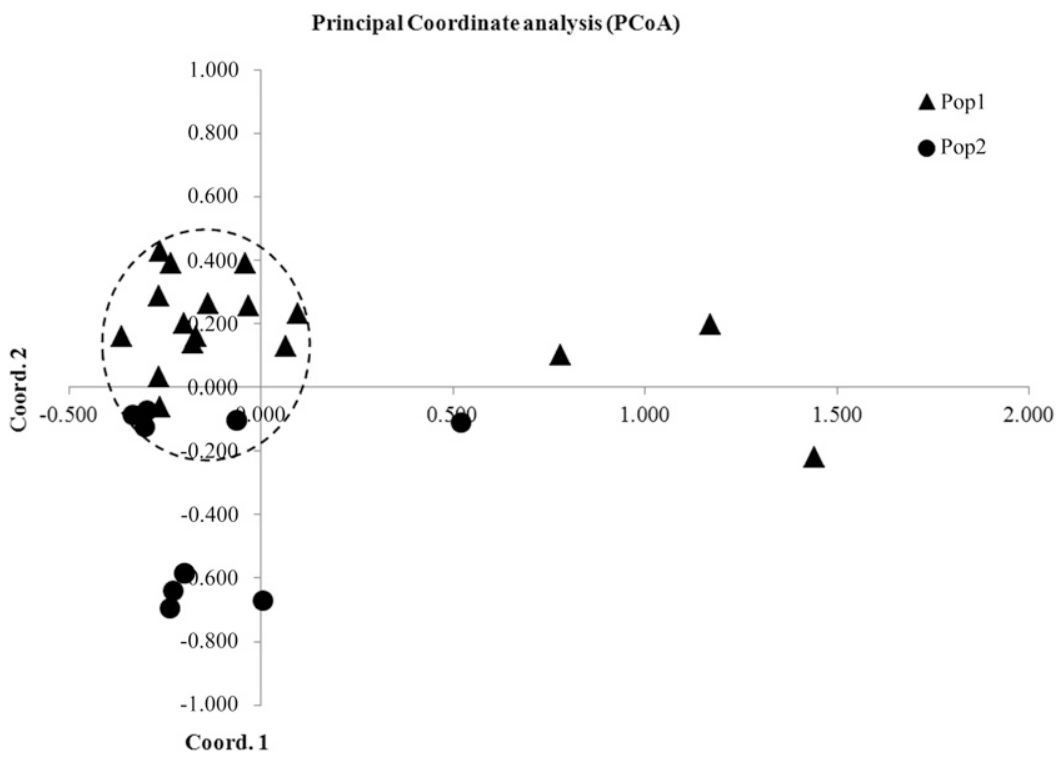

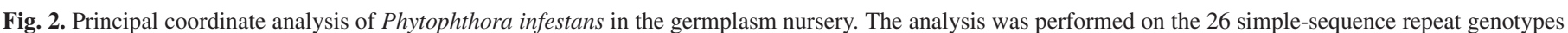

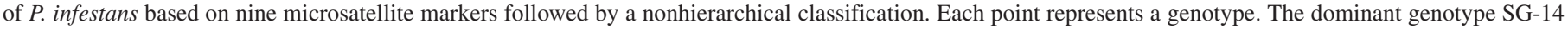

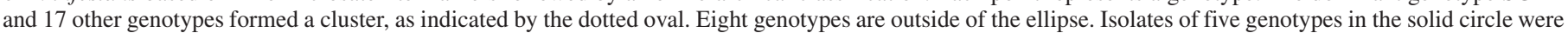

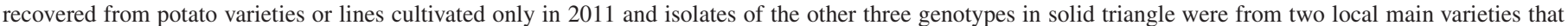
have been planted in northern China for nearly 20 years. Pop 1 refers to P. infestans population in 2010 and Pop 2 refers to P. infestans population in 2011. 
clonal. Furthermore, only three A1 isolates recovered from local potato varieties were detected in 2010 and no A1 isolates were detected in 2011. The low frequency and subsequent lack of detection of A1 mating type in the germplasm nursery may be restricting the connection between two mating types and subsequently lack of sexual recombination. Additionally, no sexual oospore structures were observed in infected plant tissues (leaves were the primary tissue examined) in commercial potato fields in northwestern China (data not shown). In summary, we can conclude that the P. infestans population in the germplasm nursery was clonal.

There appeared to be migration of $P$. infestans populations in the germplasm nursery, because the majority of genetic variation was found within rather than among populations. Low differentiation was also detected between the two annual $P$. infestans populations, which is indicative of migration. This was further supported by the high value of $\mathrm{Nm}$ between pairwise comparison of isolates sampled in 2 years. Second, all of the $P$. infestans isolates from the germplasm nursery were collected at the start of the disease epidemic (less than $10 \%$ of disease incidence); therefore, the contribution of aerial dispersion of asexual sporangia to the population structure was likely limited. Finally, and most importantly, specific multilocus SSR genotypes of $P$. infestans isolates recovered from corresponding potato varieties or lines were detected in both years (populations). The vast majority of the $P$. infestans isolates $(93.8 \%)$ recovered from the common varieties or lines in 2011 shared the same SSR genotypes (SG-14 and SG-25) with those recovered in the previous year, indicating the persistence of inoculum sources in the germplasm nursery. The most likely scenario is that the 2011 population resulted from infected potato seed tubers. This is because potato seed tubers of the 23 common varieties or lines cultivated in 2011 were directly obtained in the germplasm nursery in the previous year and volunteer potato plants are uncommon in the area due to cold winters. Our findings indicated that the pathogen survives as a clonal lineage, and infected seed tubers, as a main inoculum source, contributed significantly to disease occurrence. Therefore, disease control measures should be directed toward pathogen-free planting material so as to reduce loss caused by late blight.

The most common pathotype (1.2.3.4.5.6.7.8.9.10.11) was virulent on all $11 R$ genes. Isolates of this pathotype were distributed on the majority of varieties or lines in the germplasm nursery. In China, this pathotype was first detected in a collection of 136 field P. infestans isolates during 2000 to 2003 (Zhao et al. 2007). Guo et al. (2009) also reported frequent detection of this pathotype among isolates collected in Inner Mongolia in 2003. Isolates that are virulent on all $11 R$ genes, which have been detected at different times and locations in China, were not identical when other characteristics were taken into account (Guo et al. 2009; Li et al. 2009). In our study, most of the isolates virulent on all $11 R$ genes were A2 or self-fertile, mtDNA haplotype Ia, and belonged to different SSR genotypes based on the nine microsatellite loci. This is consistent with the notion that virulence variation in $P$. infestans is independent of mating type or SSR genotypic background. In Nicaragua, high genetic diversity was observed in a clonal lineage of $P$. infestans and was likely due to selection pressure imposed by potato cultivars carrying different $R$ genes (Blandón-Diaz et al. 2012). However, there is no information on the composition of resistance genes in main potato cultivars in China.

In this study, the self-fertile isolates were predominant in 2 years and the isolates were recovered from 63 potato varieties or lines in the germplasm nursery, with a frequency of 63.7 and $98.2 \%$ in 2010 and 2011, respectively. This scenario is similar to the result initially described by Ma et al. (2013) with P. infestans isolates collected in the same potato germplasm nursery in 2009. Han et al. (2013) reported that self-fertile isolates were also detected in commercial potato fields in Gansu, northwestern China. The cause for high frequency of self-fertile isolates remains unknown and needs to be further investigated.
Knowledge of pathogen population structure and dynamics is useful for the development of integrated management strategies. Continued late blight monitoring by growers, advisors, and plant health inspectors is vital to aid in making disease control decisions. Based on our current study, both the regulation of seed tuber quality and proper fungicide treatment of seed tubers will improve management of late blight of potato in northwestern China.

\section{ACKNOWLEDGMENTS}

We thank D. Cooke (The James Hutton Institute, United Kingdom) and F. Govers (Wageningen University, The Netherlands) for providing genomic DNA of reference P. infestans isolates, L. Jin (Institute of Vegetables and Flowers, Chinese Academy of Agricultural Sciences, Beijing, China) for providing us with potato differentials, N. J. Grünwald (Oregon State University, United States) for helpful advice on genetic data analysis, and Q. Wang and J. Jia for technical assistance on the use of software. This work was supported by China Agriculture Research System (CARS-10), Special Fund for Agro-scientific Research in the Public Interest of China (201303018), and National Natural Science Foundation of China (31272020)

\section{LITERATURE CITED}

Agapow, P. M., and Burt, A. 2001. Indices of multilocus linkage disequilibrium. Mol. Ecol. Notes 1:101-102.

Andersson, B. 2007. Sexual reproduction in Phytophthora infestans. Doctoral thesis, Swedish University of Agricultural Sciences, Uppsala, Sweden.

Andersson, B., Widmark, A. K., Yuen, J. E., Nielsen, B., Ravnskov, S., Kessel, G. J. T., Evenhuis, A., Turkensteen, L. J., Hansen, J. G., and Lehtinen, A. 2009. The role of oospores in the epidemiology of potato late blight. Acta Hortic. 834:61-68

Balloux, F., Lehmann, L., and De, M. T. 2003. The population genetics of clonal and partially clonal diploids. Genetics 164:1635-1644.

Bassam, B. J., and Gresshoff, P. M. 2007. Silver staining DNA in polyacrylamide gels. Nat. Protoc. 2:2649-2654.

Birky, C. W. 1996. Heterozygosity, heteromorphy, and phylogenetic trees in asexual eukaryotes. Genetics 144:417-437.

Blandón-Diaz, J. U., Widmark, A. K., Hannukkala, A., Andersson, B., Hogberg, N., and Yuen, J. E. 2012. Phenotypic variation within a clonal lineage of Phytophthora infestans infecting both tomato and potato in Nicaragua. Phytopathology 102:323-330.

Brurberg, M. B., Elameen, A., Le, V. H., Naerstad, R., Hermansen, A., Hannukkala, A., Nielsen, B., Hansen, J., and Andersson, B. 2011. Genetic analysis of Phytophthora infestans populations in the Nordic European countries reveals high genetic variability. Fungal Biol. 115:335-342.

Caten, C., and Jinks, J. 1968. Spontaneous variability of single isolates of Phytophthora infestans. I. Cultural variation. Can. J. Bot. 46:329-348.

Chen, R. S., and McDonald, B. A. 1996. Sexual reproduction plays a major role in the genetic structure of populations of the fungus Mycosphaerella graminicola. Genetics 142:1119-1127.

Danies, G., Small, I. M., Myers, K., Childers, R., and Fry, W. E. 2013. Phenotypic characterization of recent clonal lineages of Phytophthora infestans in the Unites States. Plant Dis. 97:873-881.

Drenth, A., Janssen, E., and Govers, F. 1995. Formation and survival of oospores of Phytophthora infestans under natural conditions. Plant Pathol. 44:86-94.

Drenth, A., Tas, I. C., and Govers, F. 1994. DNA fingerprinting uncovers a new sexually reproducing population of Phytophthora infestans in the Netherlands. Eur. J. Plant Pathol. 100:97-107.

Flier, W. G., Kroon, L., Hermansen, A., Van Raaij, H. M. G., Speiser, B., Tamm, L., Fuchs, J. G., Lambion, J., and Andrivon, D. 2007. Genetic structure and pathogenicity of populations of Phytophthora infestans from organic potato crops in France, Norway, Switzerland and the United Kingdom. Plant Pathol. 56:562-572.

Fry, W. 2008. Phytophthora infestans: The plant (and $R$ gene) destroyer. Mol. Plant Pathol. 9:385-402.

Goodwin, S. B. 1997. The population genetics of Phytophthora. Phytopathology 87:462-473.

Goodwin, S. B., Spielman, L. J., Matuszak, J. M., Bergeron, S. N., and Fry, W. E. 1992. Clonal diversity and genetic differentiation of Phytophthora infestans populations in northern and central Mexico. Phytopathology 82:955-961.

Griffith, G. W., and Shaw, D. S. 1998. Polymorphisms in Phytophthora infestans: Four mitochondrial haplotypes are detected after PCR amplification of DNA from pure cultures or from host lesions. Appl. Environ. Microbiol. 64: 4007-4014. 
Grünwald, N. J., Flier, W. G., Sturbaum, A. K., Garay-Serrano, E., van den Bosch, T. B. M., Smart, C. D., Matuszak, J. M., Lozoya-Saldana, H., Turkensteen, L. J., and Fry, W. E. 2001. Population structure of Phytophthora infestans in the Toluca valley region of central Mexico. Phytopathology 91:882-890.

Grünwald, N. J., Goodwin, S. B., Milgroom, M. G., and Fry, W. E. 2003. Analysis of genotypic diversity data for populations of microorganisms. Phytopathology 93:738-746.

Guo, J., Lee, T. D., Qu, D. Y., Yao, Y. Q., Gong, X. F., Liang, D. L., Xie, K. Y., Wang, X. W., and Govers, F. 2009. Phytophthora infestans isolates from Northern China show high virulence diversity but low genotypic diversity. Plant Biol. 11:57-67.

Guo, L. Y., Zhu, X. Q., Hu, C. H., and Ristaino, J. B. 2010. Genetic structure of Phytophthora infestans populations in China indicates multiple migration events. Phytopathology 100:997-1006.

Han, M., Liu, G., Li, J. P., Govers, F., Zhu, X. Q., Shen, C. Y., and Guo, L. Y. 2013. Phytophthora infestans field isolates from Gansu province, China are genetically highly diverse and show a high frequency of self fertility. J. Eukaryot. Microbiol. 60:79-88.

Hu, C. H., Perez, F. G., Donahoo, R., McLeod, A., Myers, K., Ivors, K., Secor, G., Roberts, P. D., Deahl, K. L., Fry, W. E., and Ristaino, J. B. 2012. Recent genotypes of Phytophthora infestans in the eastern United States reveal clonal populations and reappearance of mefenoxam sensitivity. Plant Dis. 96:1323-1330.

Kamvar, Z. N., Tabima, J. F., and Grünwald, N. J. 2014. Poppr: An R package for genetic analysis of populations with mixed (clonal/sexual) reproduction. Peer J. 2:e281.

Knapova, G., and Gisi, U. 2002. Phenotypic and genotypic structure of Phytophthora infestans populations on potato and tomato in France and Switzerland. Plant Pathol. 51:641-653.

Lees, A. K., Wattier, R., Shaw, D. S., Sullivan, L., Williams, N. A., and Cooke, D. E. L. 2006. Novel microsatellite markers for the analysis of Phytophthora infestans populations. Plant Pathol. 55:311-319.

Li, B. J., Chen, Q. H., Lv, X., Lan, C. Z., Zhao, J., Qiu, R. Z., and Weng, Q. Y. 2009. Phenotypic and genotypic characterization of Phytophthora infestans isolates from China. J. Phytopathol. 157:558-567.

Li, Y. 2012. Multiplex SSR analysis of Phytophthora infestans in different countries and the importance for potato breeding. Doctoral thesis, Wageningen University, Wageningen, Netherlands.

Li, Y., Lee, T., Zhu, J. H., Jin, G. H., Lan, C. Z., Zhu, S. X., Zhang, R. F., Liu, B. W., Zhao, Z. J., and Kessel, G. 2013. Population structure of Phytophthora infestans in China-geographic clusters and presence of the EU genotype Blue_13. Plant Pathol. 62:932-942.
Liu, K., and Muse, S. V. 2005. PowerMarker: An integrated analysis environment for genetic marker analysis. Bioinformatics 21:2128-2129.

Ma, Y. F., Sun, J. P., Ma, L. J., Quan, J. L., and Shan, W. X. 2013. Population analysis of Phytophthora infestans collected from a potato germplasm nursery. Mycosystema 32:802-811.

Montarry, J., Andrivon, D., Glais, I., Corbiere, R., Mialdea, G., and Delmotte, F. 2010. Microsatellite markers reveal two admixed genetic groups and an ongoing displacement within the French population of the invasive plant pathogen Phytophthora infestans. Mol. Ecol. 19:1965-1977.

Peakall, R., and Smouse, P. E. 2006. GENALEX 6: Genetic analysis in Excel. Population genetic software for teaching and research. Mol. Ecol. Notes 6: 288-295.

Prospero, S., Hansen, E. M., Grünwald, N. J., and Winton, L. M. 2007. Population dynamics of the sudden oak death pathogen Phytophthora ramorum in Oregon from 2001 to 2004. Mol. Ecol. 16:2958-2973.

Rambaut, A., and Drummond, A. 2010. FigTree v1. 3.1. Institute of Evolutionary Biology, University of Edinburgh, Edinburgh, United Kingdom.

Smith, J. M., Smith, N. H., O’Rourke, M., and Spratt, B. G. 1993. How clonal are bacteria? Proc. Natl. Acad. Sci. USA 90:4384-4388.

Tantius, P. H., Fyfe, A. M., Shaw, D. S., and Shattock, R. C. 1986. Occurrence of the A2 mating type and self-fertile isolates of Phytophthora infestans in England and Wales. Plant Pathol. 35:578-581.

Team, R. C. 2011. R: A Language and Environment for Statistical Computing. Online publication. http://www.R-project.org/

Therrien, C., Tooley, P., Spielman, L., Fry, W. E., Ritch, D. L., and Shelly, S. E. 1993. Nuclear DNA content, allozyme phenotypes and metalaxyl sensitivity of Phytophthora infestans from Japan. Microbiol. Res. 97: 945-950.

Tian, Y. E., Sun, J. P., Li, H. P., Wang, G., Ma, Y. F., Liu, D. D., Quan, J. L., and Shan, W. X. 2014. Dominance of a single clonal lineage in the Phytophthora infestans population from northern Shaanxi, China revealed by genetic and phenotypic diversity analysis. Plant Pathol. 64: 200-206.

Widmark, A. K., Andersson, B., Cassel-Lundhagen, A., Sandstrom, M., and Yuen, J. E. 2007. Phytophthora infestans in a single field in southwest Sweden early in spring: Symptoms, spatial distribution and genotypic variation. Plant Pathol. 56:573-579.

Widmark, A. K., Andersson, B., Sandstrom, M., and Yuen, J. E. 2011. Tracking Phytophthora infestans with SSR markers within and between seasons - a field study in Sweden. Plant Pathol. 60:938-945.

Zhao, Z. J., Li, C. H., Cao, J. F., Sun, D. W., Yang, M. Y., and Wang, J. 2007. Study on the virulence genes and virulence structure of Phytophthora infestans on Yunnan potato. Sci. Agric. Sin. 40:505-511. 